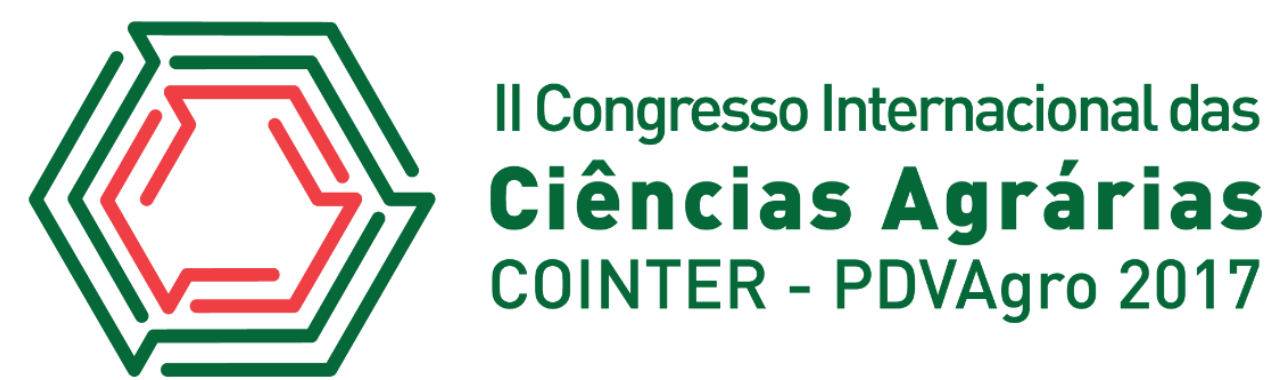

\title{
PERFIL DO CONSUMIDOR DE CARNE DO BAIRRO DE DOIS IRMÃOS NA CIDADE DO RECIFE- PERNAMBUCO
}

Apresentação: Comunicação Oral

Letícia Aline Lima da Silva; Vitor Magalhães de Mendonça Cunha Miranda; Marina Ximenes de Oliveira; Anderson Cristiano Ferreira Costa; Fernando de Figueiredo Porto Neto.

\section{Resumo}

O objetivo desta pesquisa foi analisar o perfil do consumidor e a carne mais consumida no bairro de Dois Irmãos na cidade do Recife - PE. O presente trabalho foi realizado na cidade de Recife Pernambuco e no bairro de Dois Irmãos. A coleta dos dados foi realizada no período compreendido entre os dias 12 a 15 de janeiro de 2017. A amostra foi composta por 100 entrevistados escolhidos aleatoriamente. Foi possível observar que os consumidores de carne do bairro de Dois Irmãos apresentam de forma diversificada no que se refere ao sexo, grau de escolaridade, renda e composição familiar. Foi possível constatar que a carne mais consumida foi a de aves $(60,6 \%)$, isso porque $47,5 \%$ leva em conta o preço na hora da compra. Porém a preferência do consumo de carne é a bovina $(58,5 \%)$, o modo de preparo mais utilizado é o frito $(48,6 \%)$ devido ser mais prático. Observou que $65,3 \%$ dos entrevistados preferem comprar as carnes em supermercados e um ponto importante na escolha do local da compra é a aparência e higiene do local 47,2\% e realizam compras semanal $(47,2 \%)$, por preferir um alimento mais fresco. $\mathrm{O}$ aspecto que mais é levado em conta na hora da compra é a aparência geral $(35,6 \%)$ e a cor $(42,6 \%)$. Conclui-se que o desenvolvimento desta pesquisa permitiu conhecer e avaliar o perfil dos consumidores quanto ao consumo de carne no bairro de Dois Irmãos da cidade do Recife- PE, assim pode se observar que a carne bovina a preferida pelos entrevistados em relação à de outras espécies animais, ocupando lugar de destaque na dieta do consumidor. O consumidor considera a cor o melhor indicador da qualidade da carne, sendo o principal atributo e a preferência pela compra em supermercado.

Palavras-Chave: Alimentação, Consumo, Hábito.

\section{Introdução}

A carne é um alimento de origem animal, fonte de proteínas de alto valor biológico e rica em vitaminas do complexo B e em minerais de alta biodisponibilidade como ferro e zinco (BENDER, 1991).O Brasil é considerado o segundo maior produtor mundial de proteína animal e tem no mercado externo o principal destino de sua produção (USDA, 2012). A carne está entre os alimentos mais consumidos no mundo e no Brasil, segundo dados da USDA Bradesco, o consumo de carne bovino no mundo foi de $22,5 \%$, já o Brasil teve um consumo

\footnotetext{
${ }^{1}$ Zootecnia, UFRPE, leticiaalinezoo@gmail.com

${ }^{2}$ Zootecnia, UFRN, vitorzootec01@gmail.com

${ }^{3}$ Zootecnia, UFRPE, marinaximenes2@gmail.com

${ }^{4}$ Zootecnia, UFRPE, andersonano10@hotmail.com

${ }^{5}$ Doutor, UFRPE, f_porto@hotmail.com
} 
de $38,6 \%$, a carne de frango teve um consumo no mundo de $34,6 \%$ e no Brasil $46,8 \%$ e a carne suína teve o consumo mundial de $42,9 \%$, no Brasil foi de $14,5 \%$.

A carne apresenta-se juntamente como um de alimento de ótima composição nutricional para o ser humano. Possui proteínas de alto valor biológico tanto no aspecto qualitativo como quantitativo. Rica em aminoácidos essenciais, de forma balanceada, supre aproximadamente 50\% das necessidades diárias de proteína do ser humano (Azevedo, 2008).

As pesquisas que abordam o comportamento do consumidor fazem uso das informações referentes à produção, abastecimento e dados sobre as compras dos alimentos para identificarem as práticas alimentares. Desta maneira, pesquisadores e organizações buscam conhecer os gostos, preferências, hábitos e atitudes dos consumidores, para que se possam apontar tendências e perspectivas em relação ao comportamento de consumo (Sproesser et al., 2006).

Muitos são os fatores que podem interferir na escolha do tipo de carne e corte a ser comprado, como renda, idade, grau de escolaridade, estado civil, número de filhos, local de residência, sexo, praticidade de preparo e ocasião a ser consumida. O valor nutricional e os benefícios à saúde também estão sendo pontos determinantes na escolha da carne, pois os consumidores estão cada vez mais informados e exigentes de qualidade nos alimentos (PIRES,2015).

Em função destes aspectos, o objetivo foi analisar o perfil do consumidor e a carne mais consumida na cidade do Recife - PE

\section{Fundamentação Teórica}

Recife possui uma área de aproximadamente $217 \mathrm{~km}^{2}$, está localizado às margens do oceano Atlântico, e possui uma população de 1.546 .516 pessoas. (Prefeitura do Recife)

Devido ao tamanho da cadeia produtiva que é composta pela produção de aves, suínos, bovinos e pescados e sua a grande variedade de produtos disponível surgiu a certificação para diminuir a desconfiança dos consumidores em relação à qualidade e o valor nutricional (BRANDÃO et al., 2010).

A rastreabilidade é uma ferramenta de certificação que pode passar para os consumidores informações sobre os produtos e também dar garantias destes produtos (BRANDÃO et al., 2010), pode passar informações sobre local e condições que o animal foi abatido e até questões de bemestar animal (BRANDÃO et al., 2010).

O comportamento alimentar é complexo, pois inclui vários determinantes que vão desde os recursos financeiros disponíveis para o acesso dos alimentos até as preferências e crenças da população sobre com o que se alimentar.

Melhores condições socioeconômicas, como maior grau de escolaridade e maiores níveis de renda, estimulam melhorias na infra-estrutura e na capacidade para a aquisição dos alimentos. 
Consegue-se perceber que aqueles indivíduos com melhor situação socioeconômica têm uma dieta mais diversificada e geralmente consomem carnes com maior frequência do que aqueles indivíduos com menores condições.

Em conjunto com os fatores socioeconômicos, os fatores demográficos agem diretamente na determinação do consumo. Vale à pena observar a diferença existente no consumo entre os gêneros e a faixa etária. Entre os homens, em qualquer estudo revisado nesse projeto, houve maior consumo de carnes, em termos de quantidade e frequência, quando comparados às mulheres.

A tomada de decisão para compra da carne é influenciada por objetivos pessoais, metas, comportamento, atitudes e necessidades da família (BRANDÃO et al., 2010). Este processo ainda sofre influência do ambiente físico e social do momento da compra, o tempo disponível para compra, o propósito e ainda as condições momentâneas como humor, saúde e dinheiro (PENNA, 2008).

É notável que em países como o Brasil, embora o consumo esteja ainda bem abaixo comparado aos níveis de consumo da América do Norte e da maioria dos países industrializados, as dietas estejam cada vez mais ricas e diversificadas, incluindo a carne.

Porém, para a maioria das pessoas no mundo, particularmente nos países em desenvolvimento, a ingestão desse alimento ainda é necessária para suprir deficiências nutricionais.

Segundo BARCELLOS (2007), nos últimos anos houve um crescimento no número de pesquisas com consumidores de alimentos, principalmente os alimentos de origem animal. Este aumento nas pesquisas pode ser explicado por surtos de doenças animais, os pros e contras do consumo de proteína animal na nutrição e na saúde das pessoas, as mudanças no padrão de consumo e a entrada de novos membros de culturas diferentes no bloco econômico (BARCELLOS, 2007).

As pesquisas servem para auxiliar o desenvolvimento de novos produtos, inovações em um produto, auxílio nas decisões de preço e identificação de alternativas mais interessantes de distribuição e publicidade, o consumidor precisa ser estudado (RAIMUNDO \& BATALHA, 2012).

Conforme passa o tempo, os consumidores tendem a ser mais exigentes, e com isso o mercado tem que se adequar a esta exigência produzindo com alta qualidade, maior valor agregado e maior conveniência (HEINEN, 2013). A qualidade dos produtos de origem animal não depende apenas de um elo da cadeia produtiva, e sim de todos os elos desde o nascimento do animal até a mesa do consumidor (BARCELLOS, 2004).

Os recursos econômicos gastos com a alimentação, em termos de mercado, são consideráveis, perfazendo um montante bastante superior àqueles relativos a outros setores como o automobilístico, o eletrônico ou o de armamento (PROENÇA, 2007). 


\section{Metodologia}

Foi realizada uma pesquisa "Survey", a qual foi utilizada para a obtenção de informações por intermédio de uma entrevista com os participantes, na qual foram feitas inúmeras perguntas acerca do tema abordado por meio da aplicação de um questionário estruturado para obter uma padronização do processo de coleta de dados (Francisco et al., 2007).

O presente trabalho foi realizado na cidade de Recife - Pernambuco e no município de Dois Irmãos. A coleta dos dados foi realizada no período compreendido entre os dias 12 a 15 de janeiro de 2017, as entrevistas ocorreram em dias alternados. Inicialmente foi elaborado um questionário de múltipla escolha composto de 15 perguntas fechadas, onde foram abordados vários aspectos do consumo de carne.

Tratou-se de uma pesquisa de caráter exploratório que se apoiou em base quantitativa realizada através de questionário estruturado direcionado exclusivamente os consumidores de carne desta região. A amostra foi composta por 100 entrevistados escolhidos aleatoriamente em diversos pontos da região.

Os dados foram processados utilizando-se o programa Excel 2013 da Microsoft $\AA$, versão for Windows 10, no qual foram feitas as análises estatísticas descritivas e inferenciais.

\section{Resultados e Discussão}

Os questionários foram respondidos pelos consumidores. A partir deles houve a contagem das respostas, classificando-se e entrelaçando-se os resultados de forma a atender o objetivo do trabalho. As respostas do questionário foram tabuladas e analisadas.

Levando em conta o sexo dos entrevistados, pode-se observar no Gráfico 1 que neste trabalho teve uma predominância do sexo feminino com 60,67\%, enquanto o sexo masculino teve uma porcentagem de $39,33 \%$.

Gráfico 1: Porcentagem do sexo dos entrevistados. Fonte: Própria

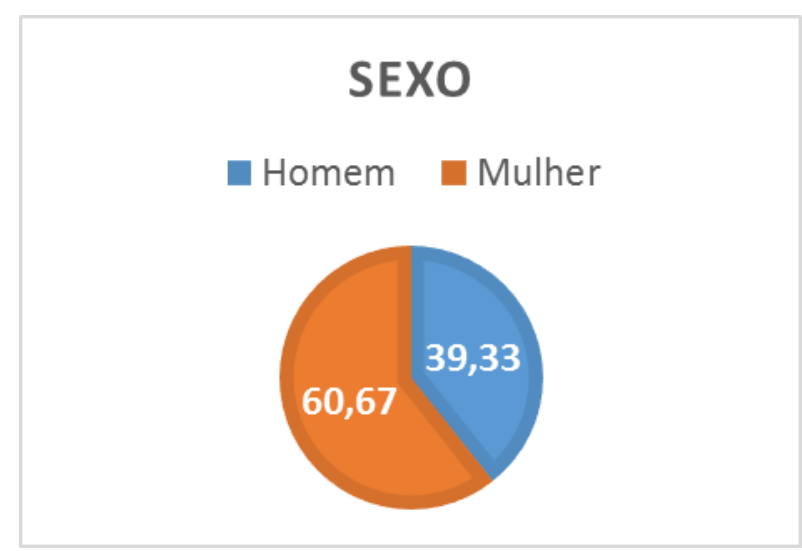


Em relação à idade, $14,47 \%$ dos consumidores entrevistados tinham entre 18 a 25 anos; 36,85\% de 26 a 40 anos; 48,68\% acima de 40 anos, sendo a faixa etária predominante. Deste modo, pode-se dizer que houve uma distribuição heterogênea quanto à faixa etária entrevistada, sendo possível obter opiniões de um número representativo de pessoas de idades diferentes.

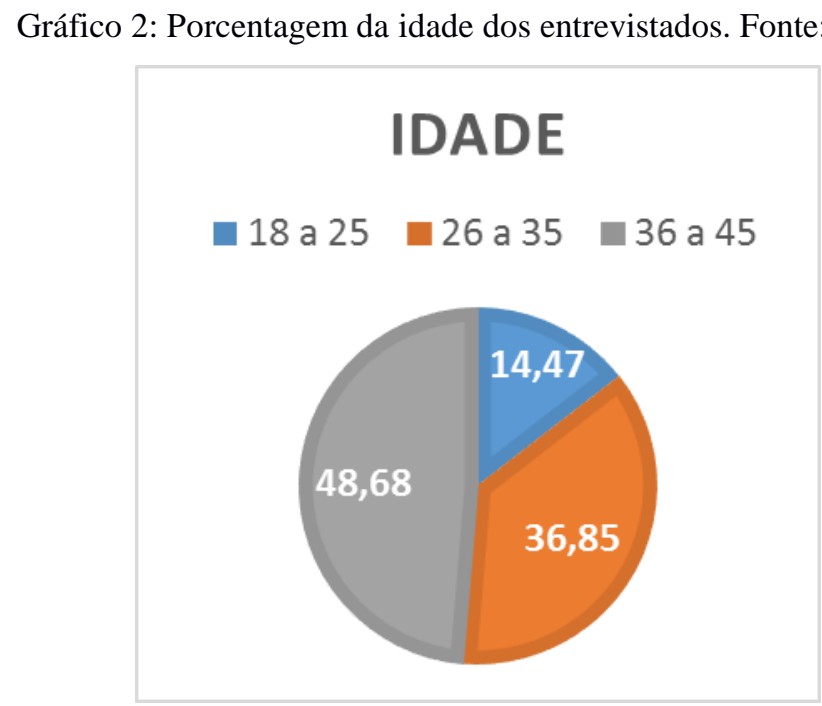

A escolaridade também foi investigada e os resultados apontam maior participação de pessoas com nível superior $(58,52 \%)$ em detrimento do nível médio $(38,95 \%)$ e fundamental $(2,23 \%)$. O grau de escolaridade pode ser largamente relacionado com o nível de informação dos consumidores que vai influenciar diretamente na hora da escolha dos alimentos.

Tabela 1: Perfil dos consumidores questionados em Recife. Fonte: Própria

\begin{tabular}{ll}
\hline Variáveis & Total Inquirido (\%) \\
\hline Dimensão do Agregado Familiar & \\
\hline 1 & 19,2 \\
2 & 39,5 \\
3 & 23,2 \\
4 & 9,3 \\
Acima de 4 pessoas & 8,9 \\
\hline Renda Familiar & \\
\hline 1 a 3 Salário mínimo & 30 \\
4 a 6 Salário mínimo & 56,8 \\
7 a 10 Salário mínimo & 13,3 \\
\hline
\end{tabular}

Conforme Tabela 01, observa-se que a grande maioria dos entrevistados apresenta renda familiar entre 4 a 6 salários mínimos com 56,8\% e a dimensão do agregado familiar que apresentou maior porcentagem $(39,5 \%)$ foi a de 2 pessoas por família. A renda e a quantidade de pessoas na casa são um fator que pode interferir quanto ao consumo de determinados alimentos, em função do preço, do poder de compra de cada família, preferência e facilidade na hora do preparo. 
BARCELLOS (2004), afirma que as pessoas que possuem menores rendas buscam mais informações quando comparadas com as de maiores rendas.

Tabela 2: Carne mais consumida em Recife. Fonte: Própria

\begin{tabular}{ll} 
Variáveis & Total Inquirido (\%) \\
\hline Carne mais consumida & \\
\hline Suíno & 9,6 \\
Bovino & 25,8 \\
Aves & 60,6 \\
Pescados & 4,0 \\
\hline Alto consumo se deve & \\
\hline Preço & 47,5 \\
Qualidade & 23,3 \\
Sabor & 9,7 \\
Valor Nutricional & 18,5
\end{tabular}

Mediante os dados da tabela 2 observou-se que a maiorias $(60,6 \%)$ possui um maior consumo de carne de aves, seguida da carne de bovina $(25,8 \%)$ e a de suíno com $9,6 \%$ e o mais baixo consumo foi de pescados (4\%). Esse consumo elevado de carne de aves de da devido ao preço e facilidade de se encontrar. Muitos afirmam que o preço e a qualidade da carne de aves estão interligados, já que a produção de aves vem crescendo e visando uma carne magra e de qualidade.

Gráfico 3: Preferência da Carne. Fonte: Própria

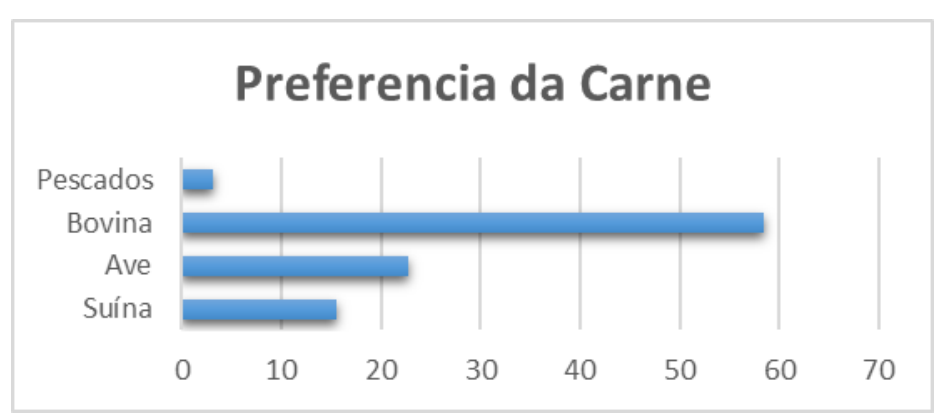

Mediante os dados do gráfico 3 observou-se que apenas 15,6\% dos consumidores consideram a carne suína como preferida para o consumo, sendo que, a maioria $(58,5 \%)$ indicou preferir a carne bovina, seguida da carne de aves $(22,8 \%)$ e carne de pescado $(3,1 \%)$. Resultados semelhantes foram encontrados por Cavalcante Neto (2003), Falleiros, Miguel e Gameiro (2008), Souza (2007), Silva e Silva (2009) e Santos et al. (2011) que desenvolveram pesquisa com consumidores de carnes questionando a preferência de consumo e, em todos os casos, a carne bovina foi citada pela maior parte da população amostral, seguida da carne de aves, carne suína e, por último, de pescado. Estes resultados podem estar relacionados aos mitos e preconceitos relacionados à carne suína, presentes inconscientemente nas preferências e hábitos dos consumidores. 
Tabela 3: Modo de preparo da Carne. Fonte: Própria

\begin{tabular}{ll} 
Variáveis & Total Inquirido (\%) \\
\hline Modo de preparo & \\
\hline Frito & 48,6 \\
Assado & 27,8 \\
Cozido & 20 \\
Outro & 3,6
\end{tabular}

Na tabela 3 estão disponíveis as formas de preparo mais utilizadas pelos consumidores. Observou-se que 48,6\% dos entrevistados mencionaram consumir a carne frita. Esta forma de preparo está relacionada à praticidade no momento de consumo, onde, em função da rotina dos consumidores, há uma crescente busca por alternativas de pratos rápidos para o consumo e, a fritura, é uma alternativa (HEINEN,2013). Contudo, 27,8\% dos entrevistados mencionaram preferir o consumo da carne assada, o que demonstra que, apesar da busca por praticidade, muitos consumidores preocupam-se com a saúde e apenas $20 \%$ preferem cozi a carne, para ficar mais saborosas segundo os entrevistados.

Tabela 4: Local de compra e escolha do estabelecimento. Fonte: Própria

\begin{tabular}{ll}
\hline Variáveis & Total Inquirido (\%) \\
\hline Estabelecimento que adquire a carne & \\
\hline Açougue/ Butique & 29,5 \\
Feiras Livre & 5,20 \\
Supermercado & 65,3 \\
Escolha do Estabelecimento & \\
\hline Preço & 35,1 \\
Aparência e higiene & 47,2 \\
Deslocamento & 17,7 \\
\hline Frequência da Compra & \\
\hline Semanal & 47,2 \\
Quinzenal & 35,1, \\
Mensalmente & 17,7 \\
\hline
\end{tabular}

$\mathrm{Na}$ Tabela 4, observa-se que grande parte dos entrevistados neste trabalho afirma comprar carnes em supermercados $(65,3 \%)$, este fato pode ocorrer devido à facilidade de compra e a disposição de outros produtos além das carnes como pode ser verificado nas pesquisas realizadas por WAGNER (2014), BARCELLOS (2002), RAIMUNDO (2013) e de BRISOLA \& CASTRO (2005).

BRANDÃO et al. (2010), afirmam que as boutiques e açougues são mais procurados quando a carne se destina a alguma ocasião especial como um churrasco, já que estes estabelecimentos possuem um atendimento personalizado. Apesar da procura por esse estabelecimento vem 
crescendo, já que a procura com qualidade vem aumentando, com isso 29,5\% dos entrevistados preferem comprar carne nesses estabelecimentos.

Quando tratamos do estabelecimento que o consumidor efetua a compra, neste é fundamental para ele a aparência do local, o atendimento e os funcionários são levados a sério na hora de escolher onde vai comprar (BARCELLOS, 2004). Como podemos ver na tabela 4 onde 47,2 escolhe o estabelecimento pela higiene do local e em segundo lugar que é observado é o preço $(35,1 \%)$.

Observou-se na avaliação dos hábitos do consumidor que a frequência de compra de carne semanal corresponde a 47,2\% (Tabela 5), mostrando que os entrevistados tem uma preferência por um alimento mais fresco .

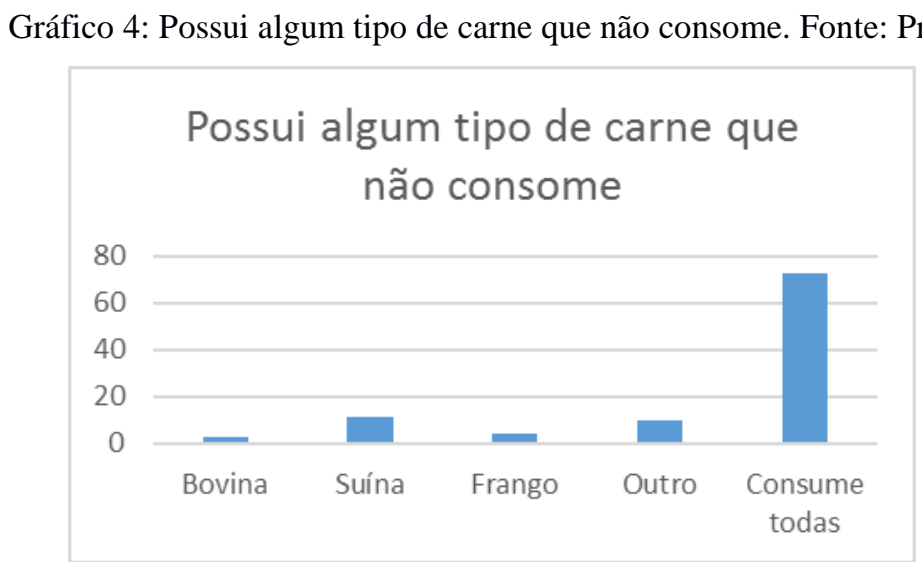

No gráfico 4 podemos ver que a carne que ainda apresenta um alto percentual que ainda não é consumida é a de suíno com 11,3\%, apesar do consumo de carne ter crescido ainda existe esse preconceito.

É importante ressaltar que a Associação Brasileira de Criadores de Suínos (ABCS) vem fazendo um forte trabalho de marketing e informação para favorecer o consumo de carne suína em nosso país, porém, este fato ainda não é muito relevante já que o consumo de carne suína no Brasil é menor que o de carne bovina e de frango, por exemplo. (RAIMUNDO \& ZEN, 2009).

A carne suína ainda é vista por muitos como uma carne que apresenta grande quantidade de gordura e prejudicial à saúde (SARCINELLI et al., 2007). E ainda muitos veem os suínos como sendo animais sujos que trazem problemas sanitários para a população (ROPPA, 2002).

Tabela 5: Aspectos e atributos levando em conta na hora da compra Fonte: Própria 


\begin{tabular}{ll}
\hline Embalagem & 22,1 \\
Validade & 15,6 \\
Aspecto visual geral & 35,6 \\
Selo de inspeção & 26,7 \\
Outro & --- \\
\hline Atributos considerados importantes na hora da & \\
compra & \\
\hline Cor & 42,6 \\
Maciez & 37,6 \\
Quantidade de Gordura & 15,5 \\
Outro & 4,05 \\
\hline
\end{tabular}

A aparência da carne, especialmente a sua cor $(42,6)$, é utilizada pelos consumidores como um importante indicador de qualidade seguida da maciez (37,6\%). Silva et al. (2007) enfatiza que Saab (1999), em trabalho realizado em Ribeirão Preto, verificou que os atributos mais importantes para os consumidores do município são, nesta ordem: cor; selo de garantia de maciez; preço; embalagem. Segundo esse autor, a cor é o atributo mais facilmente perceptível. A manutenção da cor aceitável é uma preocupação tanto dos produtores como do varejo. Inúmeros fatores afetam a cor da carne. Entre os fatores intrínsecos incluem-se a raça, a localização do músculo na carcaça e a idade do animal (Rodrigues, 2009).

\section{Conclusões}

O desenvolvimento desta pesquisa permitiu conhecer e avaliar o perfil dos consumidores quanto ao consumo de carne no bairro de Dois Irmãos da cidade do Recife- PE, assim pode se observar que o preço junto com a qualidade é um fator limitante para o consumo de carne, sendo a carne bovina a preferida pelos entrevistados em relação à de outras espécies animais, ocupando lugar de destaque na dieta do consumidor.

O consumidor considera a cor o melhor indicador da qualidade da carne, sendo o principal atributo e a preferência pela compra em supermercado.

\section{Referências}

ALBUQUERQUE, I. R. R, GOIS, G. C, CAMPOS, F. S, SILVA, T. S, MATIAS, A. G. S. Pesquisa de mercado: Hábitos de compra e consumo de carne em Senhor do Bonfim - Bahia. Nutritime. Vol. 14, No 02, mar. / abr. de 2017.

AZEVEDO, P.R.A. O valor nutricional da carne. Revista Nacional da Carne, São Paulo, n.372, p.18-29, 2008.

BARBOSA, A. C. O. Aspectos Positivos Relacionados Ao Consumo De Carne Bovina. Monografia. Universidade De Brasília. 2013. 
BARCELLOS, M. D. de. Informação e qualidade na compra de carne bovina. v.3, n.2. p.43-59, Belo Horizonte, 2004.

BARROS AJD, MENEZES AMB, SANTOS IS, ASSUNÇÃO MCF, GIGANTE D, FASSA AG, ET AL. O Mestrado do Programa de Pós graduação em Epidemiologia da UFPel baseado em consórcio de pesquisa: uma experiência inovadora. Revista Brasileira de Epidemiologia. 2008;1(suplemento 11):133-44.

BENDER A. Meatandme at products in human nutrition in developing countries. FAO FoodNutrPap1992; 53:1-91.

BLEIL, Susana Inez. O Padrão Alimentar Ocidental: considerações sobre a mudança de hábitos no Brasil. Cadernos de Debate, Campinas, V. 6, p. 1-25, 2008.

BRANDÃO, F. S.; WINCKLER, N. C.; MACHADO, J. A. D. Processo decisório da rastreabilidade da carne bovina brasileira. Sociedade Brasileira de Economia, Administração e Sociologia Rural, Campo Grande, 2010.

BRIDI, A.M. Consumo De Carne Bovina E Saúde Humana: Convergências E Divergências. Disponível em: <http://www.uel.br/grupopesquisa/gpac/pages/arquivos/consumo\%20de\%20 carne\%20revisado\%20II\%20livro\%20ronaldo.pdf >. Acessado em: 10 de out 2017.

CAMPOS, E. A, SOARES, D. P, CORDEIRO, L. F. R, COLLE, A.C, MARTINEZ, J. C. Consumo De Carne De Frango No Município De Pontes E Lacerda/MT. XXV CONGRESSO BRASILEIRO DE ZOOTECNIA.ZOOTEC 2015. Dimensões Tecnológicas e Sociais da Zootecnia. Fortaleza-CE, 27 a 29 de maio de 2015.

CAVALCANTE NETO, A. A Caracterização, avaliação e estratégias de desmistificação dos consumidores e do mercado da carne suína no Estado da Paraíba. 2003. 102 f. Trabalho de conclusão de curso (Graduação em Zootecnia) - Centro de Ciências Agrárias, Universidade Federal da Paraíba, Areia, Paraíba, 2003.

DELGADO, C. L. Rising Consumption of Meat and Milk in Developing Countries Has Created a New Food Revolution. American Society for Nutritional Sciences. 2003;133(11)(suppl):3907S-10S.

ELAAW, W. Influences on meat consumption in Australia. Appetite. 2001;36:127-36.

FALlEIROS, F. T.; MIGUEL, W. C.; GAMEIRO, A. H. A desinformação como obstáculo ao consumo da carne suína in natura. In: Congresso da Sociedade Brasileira de Economia, Administração e Sociologia Rural, 46, 2008, Acre. Anais do XLVI Congresso da Sociedade Brasileira de Economia, Administração e Sociologia Rural. Acre: SOBER, 2008.

FERNANDES, P.T, TEIXEIRA, K. V, MELO, E. S, SILVA, D. M, AZEVEDO, C. A. N, CARVALHO, L. A, VIANA, P. T, FONSECA, R. A. F. Análise Do Perfil E Preferência Do Consumidor De Carne Bovina Em Guanambi - BA e Microrregião. Disponível em: < http://faculdadeguanambi.edu.br/wp-content/uploads/2015/11/an\%c3\%81lise-do-perfil-e refer\%c3\%8ancia-do-consumidor-de-carne-bovina-em-guanambi-\%e2\%80\%93-bamicrorregi\%c3\%83o.pdf > Acessado em: 10 de out 2017.

FRANCISCO, D.C.; NASCIMENTO, V.P.; LOGUERCIO, A.P.; CAMARGO, L. Caracterização 
do consumidor de carne de frango da cidade de Porto Alegre. Ciência Rural, v.37, n.1, p. 253 $258,2007$.

HEINEN, S. M. Principais aspectos considerados por consumidores na aquisição de carne suína. Universidade Tecnológica Federal do Paraná, Medianeira, 2013.

HEINEN, S. M. Principais Aspectos Considerados Por Consumidores Na Aquisição De Carne Suína. Monografia. CURSO SUPERIOR DE TECNOLOGIA EM ALIMENTOS. UNIVERSIDADE TECNOLÓGICA FEDERAL DO PARANÁ. 2013

PENNA, L. B. Estudo do comportamento de compra dos consumidores: uma análise da utilização desta ferramenta na elevação do consumo da carne suína no Brasil. Revista FACEVV, n. 1, $2^{\circ}$ semestre, p. 41-51, 2008.

PIRES, H. V. Preferências Dos Consumidores De Carne: Um Enfoque Na Cidade De Florianópolis - SC. Monografia. Universidade Federal de Santa Catarina, Florianópolis, 2015.

Popkin BM. Reducing meat consumption has multiple benefits for the world's health. Arch Intern Med. 2009 Mar 23;169(6):543-5.

PROENÇA, R. P. C. Desafios atuais na alimentação humana. UFSC 2007

RAIMUNDO, L. M. B.; BATALHA, M. O. Determinantes do comportamento do consumidor de carnes: proposta de modelo teórico. Bento Gonçalves, 2012.

RAIMUNDO, L. M.; ZEN, S. de. Aferição do perfil do consumidor de carne suína - Estudo de caso Carrefour/ Jundiaí (SP). Sociedade Brasileira de Economia, Administração e Sociologia Rural, Campo Grande, 2009.

RODRIGUES, S.D. Pesquisa de mercado: Hábitos de consumo e perfil do consumidor de carne bovina in natura na grande Vitória. 2009. 55f. Monografia (Pós-Graduação "Latu Sensu" em Higiene e inspeção de produtos de origem animal) - Universidade Castelo Branco, Vitória, 2009.

ROPPA, L. Suinocultura mundial: situação atual e perspectivas. Pork World, v. 4, n. 25, 2012.

SAAB, M.S.M. Changes in contractual relations - an example in the beef agribusiness system in Brazil. In: WORLD FOOD AND AGRIBUSINESS FORUM AND CONGRESS, 1999, Florence, Italy. Electronic proceedings... Florence: IAMA, 1999.

SANTOS, T. M. B.; CAPPI, N.; SIMÕES, A. R. P.; SANTOS, V. A. C.; PAIANO, D.; GARCIA, E. R. M. Diagnóstico do perfil do consumidor de carne suína no município de Aquidauana-MS. Revista Brasileira Saúde Produção Animal, Salvador, v. 12, n. 1, p. 1-13. 2011.

SARCinelli, M. F.; SIlVA, L. C.; VEnTURINI, K. S. Processamento da Carne Suína. Universidade Federal do Espírito Santo - UFES, 2007. Disponível em: <http://www.agais.com/telomc/b01907_processamento_suinos.pdf >. Acesso em 23 de julho de 2013.

SARCINElli, M. F.; VEnTURINI, K. S.; SILVA, L. C. Características da Carne Suína. Universidade Federal do Espírito Santo/UFES Pró-Reitoria de Extensão, Programa Institucional de 
Extensão Boletim Técnico, 2007.

SCHNEIDER, B. C, DURO, S. M. S, ASSUNÇÃO, M. C. F. Consumo de carnes por adultos do sul do Brasil: um estudo de base populacional. Disponível em: < http://www.scielo.br/scielo.php?pid=S1413-81232014000803583\&script=sci_abstract\&tlng=p>. Acessado em: 9 de outubro 2017.

SCHNEIDER, B. C. Consumo De Carnes Pela População Adulta De Pelotas/Rs: Quem E Como Consome. Dissertação. Programa De Pós-Graduação Em Epidemiologia. Universidade Federal De Pelotas. Rio Grande Do Sul, 2010.

SILVA, D.S , SILVA, J. A., MACIEL, M. L, HOLANDA, M. A. C, HOLANDA, M. C. R, VIGODERIS, R. B, ANDRADE, A. R. S, JUNIOR, J. P. S. Comercialização E Consumo Da Carne Suína Nos Municípios De Bom Conselho E Terezinha, Pernambuco. Universidade Federal Rural de Pernambuco. Disponível em: < http://www.eventosufrpe.com.br/jepex2009/cd/resumos/R10041.pdf.> Acessado em: 9 de outubro 2017

SILVA, J. P.; SILVA, L. P. G. Estudo e avaliação do consumidor de carne suína "in natura" e industrializada na microrregião de Guarabira-PR. ACSA -Agropecuária Científica no SemiÁrido, v.05, 57-61, UFCG - Patos - PB. 2009.

SOUZA, F. B. R.; FRANÇA, A. Z.; SILVEIRA, C. R.; ZOTTI, C. M.; XAVIER, E. G. PERFIL DO CONSUMIDOR DE CARNE SUÍNA NO MUNICÍPIO DE PELOTAS-RS. XVII CIC, XI ENPOS I Mostra Cientifica. FAEM - Universidade Federal de Pelotas - Campus Universitário, 2007.

SPROESSER, R.L.; NOVAES, A.L.; BATALHA, M.O.; LAMBERT, J.L.; LIMA FILHO, D.O. Perfil do consumidor brasileiro de carne bovina e de hortaliças. In.: CONGRESSO DA SOBER, "Questões agrárias, educação no campo e desenvolvimento", XLIV, 2006, Campo Grande - MS. Anais... Campo Grande, 2006.

THOMS, E. ET AL. Perfil de consumo e percepção da qualidade da carne suína por estudantes de nível médio da cidade de Irati, PR. Revista Acadêmica: Ciências Agrárias e Ambientais, v. 8, n. 4, p. 449-459, 2010.

USDA - United States Department of Agriculture. Livestock and poultry: World markets and trade. Foreign Agricultural Service. April 2012. Disponível em: http://www.fas.usda.gov/psdonline/circulars/livestock_poultry.pdf. Acesso em: 12 dez 2012, às $18: 30$.

WAGNER, B. Preferências dos consumidores de carne bovina: uma abordagem referente às cidades de Florianópolis - SC e Botucatu - SP. Universidade Federal de Santa Catarina, Florianópolis, 2014.

ZAMBERLAN, L, SPAREMBERGER, A, BÜTTENBENDER, P. L, WAGNER, A, ZAMIN, M. As Atitudes do Consumidor de Carne: um Estudo Exploratório das Percepções e o Papel da Cultura no Consumo. XXIII Encontro da ANPAD. Rio de Janeiro/RJ - 6 a 8 de setembro de 2008. 